\title{
Current patterns of the sun protection measures adopted by nurses and the risk factors influencing their compliance
}

\author{
Hero Brokalaki $^{1}$, Evridiki Patelarou ${ }^{2 *}$, Constantine Vardavas $^{3}$, Ioannis S. Elefsiniotis ${ }^{1}$, \\ Konstantinos A. Giakoumidakis ${ }^{1}$, Eirini Brokalaki ${ }^{4}$ \\ ${ }^{1}$ Faculty of Nursing, University of Athens, Athens, Greece; \\ ${ }^{2}$ University Hospital of Heraklion, Crete, Greece; \\ ${ }^{3}$ Department of Social Medicine, Faculty of Medicine, University of Crete, Crete, Greece; \\ ${ }^{4}$ Department of Dermatology, Faculty of Medicine, University of Duisburg-Essen, Essen, Germany. \\ Email: *patelarou@edu.med.uoc.gr
}

Received 21 August 2011; revised 22 September 2011; accepted 12 October 2011.

\begin{abstract}
The incidence of skin cancer is increasing worldwide. Included in high risk group are people who have light common phenotypic factors (hair, skin, eyes), have high number of naevi, report previous sunburns and have a family history of skin cancer. Protecting the skin from the sun by wearing protective clothing, using sunscreen and avoiding sun exposure are recommended among primary preventive activities. The purpose of this study was to describe the current patterns of sun protection measures adopted by nurses and to examine the association between compliance with sun protection measures and the main risk factors of melanoma. This cross sectional study was conducted in 2007 during the Annual Greek National Conference of Nursing. Nurses most commonly chose to use sunscreen, to wear glasses, to use an umbrella or to seek for shade in order to protect themselves against sun exposure. Finally, phenotypic factors, previous sunburns and common naevi presence were found to affect nurses' attitude towards protective measures. This study poses the necessity of targeting high risk groups for melanoma through campaigns aiming to foster sun protection behaviours.
\end{abstract}

Keywords: Melanoma; Nursing; Prevention; Risk Factors; Skin Cancer

\section{INTRODUCTION}

\subsection{Literature Review}

Melanoma and non-melanoma skin cancer consist the most common types of cancer in white populations. The incidence of cutaneous melanoma has increased rapidly over the past decades, specifically $85 \%$ more than any other major cancer [1-2]. The exact etiology of skin cancer is unknown [3] with childhood and adolescent years identified as key periods in the etiology of subsequent melanoma [4-5]. Exposure to ultraviolet (UV) radiation has been linked with an increased risk of developing skin cancer [6-7]. UV exposure during childhood seems to be a main factor that induces mutations in the melanocytes that are associated with an increased induction of nevi and an increased risk for the development of melanoma. Furthermore, intense intermittent sunburns and sunburn history have been also strongly implicated as key factors in the development of melanoma [8-9]. Individual phenotypic characteristics, including skin, hair and eye colour are strongly related to sensitivity to UV radiation. Persons with a light complexion are considerably more photosensitive than persons who have dark hair, iris and skin colour, respectively. Research has indicated that increased sun exposure is associated with an increased number of common naevi in children [10-11]. Light-skinned children who are exposed to sunlight increase their number of naevi and the risk for developing melanoma later in life [12]. Other studies have also demonstrated that frequent childhood sunburn and family skin cancer history are also two other very important risk factors for the development of malignant melanoma [13-14].

Overall, primary prevention of skin cancer is focused on the reduction of exposure to major risk factors [15]. Key sunburn prevention messages have focused on getting people to wear hats and long-sleeved clothes, and/or stay in the shade during peak hours of the day. Sunscreen has been recommended as an alternative means of protection in situations where clothing may not be desirable or appropriate [15-16]. Most current guidelines on the primary prevention of skin cancer include protec- 
tive clothing, correctly applied and reapplied sunscreen, and the use of a hat.

Factors that have been noted to predict differences in regards to sun exposure patterns and compliance with the use of protective measures include age, sex and educational status [17]. Young people have been identified as a high risk group for skin damage that may lead to skin cancer later in life [17]. Several studies suggest that the use of hats, protective clothing and seeking shade as measure of sun protection increased with age [18]. A recent study in Greece revealed also that younger age groups were more likely to be exposed to sun whereas females used sunscreen more commonly than males [19]. Similarly, a number of international studies have underlined that women and people with higher socio-economic status are more likely to use sunscreen [18-26]. In addition, people who perceived themselves as at risk for skin cancer and those with sun-sensitive skin have been found to adopt protective measures against sun exposure more frequently than others [18,22,24,27].

\subsection{The Purpose of This Study}

The primary aim of this study was to describe the current patterns of sun protection used by nurses in Greece, for primary prevention of skin cancer. Furthermore a secondary aim of this study was to examine the possible association between compliance with sun protection measures and risk factors for the development of melanoma.

\section{METHODOLOGY}

\subsection{Sample and Sampling Procedure}

This cross sectional study was conducted in May of 2007 during the Annual Greek National Conference of Nursing. Based on the participation rates of previous years' conferences, it was estimated that 3000 nurses would participate in the conference coming from different areas of Greece and of different nursing specialties. Out of the approximate 3000 nurses that participated in the conference, one in six nurses $(n=500)$ were requested to complete a questionnaire regarding risk factors and protective measures they use against sun exposure. Out of the 500 nurses, 349 accepted to participate (69.8\% response rate) and completed the questionnaire while due to missing data 45 of the questionnaires were excluded from the analysis. As a result the final sample of the study was 304 nurses. A cover letter explaining the aim of the study was provided and an informed consent form was obtained from each participant.The study protocol was approved by the Ethical Committee of National and Kapodistrian University of Athens.

\subsection{Data Collection}

The survey instrument was a questionnaire developed for the purposes of this study and was based on the current relevant literature. It was reviewed by two dermatologists, experts in the field and two nurses with a specialty in dermatology-nursing. The final questionnaire was pretested as part of a pilot study conducted among nursing students who accepted to participate as volunteers and all items were assessed for face validity by health survey experts. The final questionnaire included questions referent to the socio-demographic characteristics of the participants, their years at work and their educational level. In addition to the above, the questionnaire also included questions regarding the nurses' main risk factors for skin cancer development and the protective measures against sun exposure that they usually adapt.

\subsection{Data Analysis}

The descriptive data is presented as mean \pm standard deviation for continuous variables and in percentages (n) for categorical. Chi-squared tests $\left(\mathrm{x}^{2}\right)$ were used during the univariate comparisons while all reported analyses are based on two sided tests, with statistical significance noted at $p<0.05$. To model the factors that influence the adaptation of personal protective measures against sun exposure, logistic regression models were applied so as to provide odds ratios (OR) and 95\% confidence intervals (95\% CI) after adjusting for age, gender and educational status. The statistical package Stata 10.0 was used to perform the analysis.

\section{FINDINGS}

Regarding the study populations characteristics, $85.2 \%$ were female and $14.8 \%$ male and the average age was $33.9 \pm 6$ years. As for their level of education, more than $80 \%$ were of higher education (13\% had a postgraduate degree, $11 \%$ a degree from a university and $60 \%$ a degree from a technological educational institute) while $16 \%$ were nurse assistants from secondary education. Finally, almost half of the sample was married (59\%) and urban area residents (53\%) (Table 1).

Regarding the nurses' main risk factors for the development of melanoma, 39\% reported light skin colour while the percentages for eye and hair light colour were lower (28\%, 18\% respectively) as depicted in Table 2. Almost one third reported the presence of more than five common naevi (32\%) while 62\% reported sunbathing during summer. Among nurses 38\% reported previous sunburns during childhood which consist one of the most important risk factors for the development of skin cancer. The majority of the population reported the use of sunglasses, umbrella or shade, and sunscreen to protect themselves against sun exposure (85\%, 83\% \& 81\% respectively) as seen in Table 3 . Regarding clothing as 
Table 1. Socio-demographic characteristics of the study population.

\begin{tabular}{cc}
\hline & $\mathrm{n}(\%)$ \\
\hline Gender & $45(14.8)$ \\
Fale & $259(85.2)$ \\
Age & \\
20 - 29 & $63(20.7)$ \\
30 - 39 & $102(33.6)$ \\
40 - 49 & $98(32.2)$ \\
$>50$ & $41(13.5)$ \\
Marital status & $178(58.6)$ \\
Married & $126(41.4)$ \\
Unmarried & $162(53.3)$ \\
Educational status & $23(7.6)$ \\
Secondary & $49(16.1)$ \\
Technological & $183(60.2)$ \\
University & $33(10.9)$ \\
Postgraduate & $39(12.8)$ \\
Residence & \\
Urban & \\
\hline Rural & \\
\hline .urban & \\
\hline
\end{tabular}

protective measure the use of a skirt or a trouser during sun exposure was the most common (41\%) while hat use was a choice for the $28 \%$ of the population and sleeves' use was preferred by the $11 \%$ of the population.

Females were found to use sunglasses and sunscreen more than males and this finding was statistically significant ( $p=0.04$ and $p<0.001$, respectively). Age was also found to affect the use of protective measures with those aged between 30 - 50 found to use umbrella/shade and clothing to protect themselves from sun exposure more than those younger than 30 and older than 50 ( $p<$ 0.05) (Table 4). A multiple logistic regression analysis was used to evaluate the effect of the having a risk factor for skin cancer on the nursing staff's compliance in the use of protective measures against sun exposure. As seen in Table 5, nurses with light eye colour were more likely to use sunscreen with an odds ratio of 3.4 (95\% CI: 1.4 8.3) while light skin colour was also associated with increased use of sunscreen (OR 1.6 95\% CI: 1.1 - 3.1) and protective clothing including a hat, sleeves and skirt
Table 2. Risk factors for melanoma among Greek nurses.

\begin{tabular}{|c|c|}
\hline & n (\%) \\
\hline \multicolumn{2}{|l|}{ Eye color } \\
\hline Black/Brown & $220(72.4)$ \\
\hline Blue/Grey/Green & $84(27.6)$ \\
\hline \multicolumn{2}{|l|}{ Hair color } \\
\hline Black/Brown & 248 (81.6) \\
\hline Blond & $56(18.4)$ \\
\hline \multicolumn{2}{|l|}{ Skin color } \\
\hline Light & $118(38.8)$ \\
\hline Dark & $186(61.2)$ \\
\hline \multicolumn{2}{|l|}{ Personal skin cancer history } \\
\hline Yes & $2(0.7)$ \\
\hline No & 302 (99.3) \\
\hline \multicolumn{2}{|l|}{ Familial skin cancer history } \\
\hline Yes & $15(4.9)$ \\
\hline No & $289(95.1)$ \\
\hline \multicolumn{2}{|l|}{$\begin{array}{l}\text { Previous sunburns during } \\
\text { childhood }\end{array}$} \\
\hline Never & $187(61.5)$ \\
\hline $1-2$ & $86(28.3)$ \\
\hline $3-4$ & $18(5.9)$ \\
\hline $4+$ & $11(3.6)$ \\
\hline \multicolumn{2}{|l|}{ Common naevi } \\
\hline Less than 5 & $123(40.5)$ \\
\hline $6-10$ & $46(15.1)$ \\
\hline $11-20$ & $19(6.3)$ \\
\hline$>20$ & $36(11.8)$ \\
\hline I have never counted them & $40(13.2)$ \\
\hline I don't know & $40(13.2)$ \\
\hline \multicolumn{2}{|l|}{ Sunbathing } \\
\hline Yes & $188(61.8)$ \\
\hline No & $116(38.2)$ \\
\hline
\end{tabular}

or trousers with an OR of 1.3 (95\% CI: 1.2 - 2.2), 2.7 (95\% CI: 1.3 - 5.8) and 1.5 (95\% CI: 1.0 - 2.4), respectively. Those who reported previous sunburns were also more likely to use an umbrella or to seek for shade (OR 3.1 95\% CI: 1.4 - 6.8), to wear a hat 2.0 (95\% CI: 1.2 3.3) and sleeves 2.4 (95\% CI: 1.2 - 5.1) to protect themselves. On the other hand, the presence of common naevi 
Table 3. Protective measures against sun exposure among greek nurses.

\begin{tabular}{cc}
\hline & $\mathrm{n}(\%)$ \\
\hline Umbrella/shade & $52(17.1)$ \\
Never/Rarely/Sometimes & $252(82.9)$ \\
Often/Always & \\
Sunglasses & $47(15.5)$ \\
Never/Rarely/Sometimes & $257(84.5)$ \\
Often/Always & \\
Hat & $218(71.7)$ \\
Never/Rarely/Sometimes & $86(28.3)$ \\
Often/Always & \\
Long sleeves & $270(88.8)$ \\
Never/Rarely/Sometimes & $34(11.2)$ \\
Often/Always & \\
Skirt or trousers & $180(59.2)$ \\
Never/Rarely/Sometimes & $124(40.8)$ \\
Often/Always & \\
Sunscreen & \\
Never/Rarely/Sometimes & \\
Often/Always & $(80.6)$ \\
\hline
\end{tabular}

was found to increase the likelihood of wearing a hat or sleeves during sun exposure OR 1.1 (95\% CI: 0.6 - 1.9) and 1.7 (95\% CI: 1.2 - 4.0). All the above correlations were adjusted for age, gender and educational status, as possible confounders.

\section{DISCUSSION}

Our study indicated an increased number of high risk group nurses in Greece for the development of skin cancer, since almost $40 \%$ were of light skin colour and reported previous sunburns during childhood. Furthermore the nurses commonly chose to use sunscreen, to wear glasses, to use an umbrella or to seek shade in order to protect themselves from sun exposure. Finally, our results revealed that main socio-demographic characteristics such as gender and age and main risk factors including light eye and skin color, previous sunburns and the presence of common naevi robustly affect the attitude of nurses towards the use of protective measures against sun exposure. Similarly with other studies, sunscreen was one of the most commonly used protective measures [29-30] whereas females were more likely to use sunscreen compared to males [31-33]. Moreover, our results revealed that older ages were more compliant with sun protection measures and this is in accordance with the results of other studies which reported increased use of hats, protective clothing and seeking for shade as protective measures among older ages [34-35].

Phenotypic factors and the number of common naevi are very important independent risk factors for the occurrence of melanoma. A recent study performed in a Greek sample observed that fair skin and intermittent sun exposure during childhood were positively related to the risk of melanoma where as an elevated count of common melanocytic nevi and the presence of clinically atypical nevi consisted an independent risk factor of melanoma [36]. Several constitutional characteristics are highly inter-related, and possibly interact with each other in determining individual sun exposure sensitivity and, ultimately, melanoma cancer risk. Thus, the individual characteristics and the reaction of unprotected skin to mid-day summer sunlight are often analysed as risk factors and important confounders, respectively, in epidemiological studies on skin cancer and melanoma. Clearly hair and eye colours cannot be considered directly in a causal relationship with melanoma and are likely to be risk factors by virtue of their correlation with skin phenotype [37].

Sunburn is an inflammatory reaction that arises following acute exposure of the skin to sun exposure and is as a biological marker of high dose of ultraviolet radiation penetrating to the melanocytes at the base of the epidermis [38]. The number of participants that reported previous sunburns was high (38.5\%) while recent studies have also revealed that the percentages of children and adolescents who report sunburn during summer is actually high [39-40]. Numerous common naevi might indicate a greater genetic tendency to form melanoma. Although no major gene conferring an increasing risk has been identified (except for CDKN2A and CDK4 in melanoma-prone families) the possibility that some of the genes associated with naevi may play a direct role in melanoma progression cannot be excluded. In addition, multiple naevi might indicate that previous exposure to environmental agents, such as increased sun exposure, has occurred, thereby independently causing both a large number of naevi and an increased risk of melanoma formations [37]. The melanoma risk of melanoma is strongly related to the number of naevi, which are increased in individuals with high levels of sun exposure. Thus, naevi may lie in the causal pathway between sun exposure and melanoma and in this case, the adjustment for naevi would not be appropriate because it would decrease the true association [41].

Although there are a number of factors that predict solar protective behaviour in this sample, there are rela- 
Table 4. Main socio-demographic characteristics and protective measures compliance.

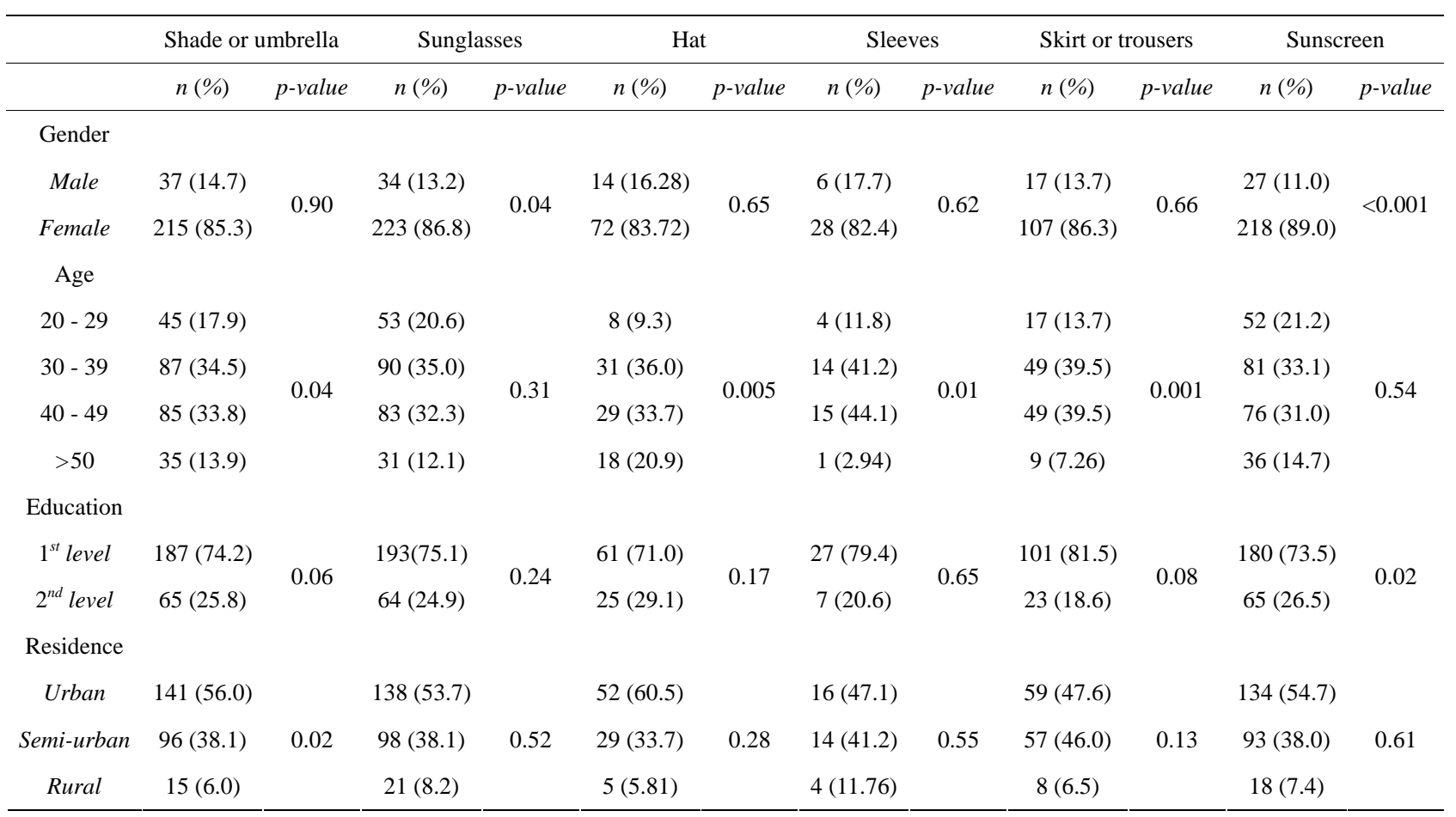

Table 5. Adjusted $\dagger$ odds ration (OR) and 95\% confidence intervals (CI) for compliance with the protective measures and melanoma risk factors.

\begin{tabular}{|c|c|c|c|c|c|c|}
\hline & Shade or umbrella & Sunglasses & Hat & Sleeves & Skirt or trousers & Sunscreen \\
\hline \multicolumn{7}{|c|}{ Eye color } \\
\hline Dark & reference & reference & reference & reference & reference & reference \\
\hline Light & $0.44(0.23-1.00)$ & $0.46(0.23-1.00)$ & $1.29(0.73-2.25)$ & $0.81(0.35-1.90)$ & $0.74(0.43-1.25)$ & $3.37(1.36-8.33)$ \\
\hline \multicolumn{7}{|c|}{ Skin color } \\
\hline Dark & reference & reference & reference & reference & reference & reference \\
\hline Light & $1.09(0.58$ - 2.07) & $0.21(0.10-1.03)$ & $1.32(1.18-2.23)$ & $2.74(1.29-5.81)$ & $1.48(1.00-2.39)$ & $1.62(1.10-3.14)$ \\
\hline \multicolumn{7}{|c|}{ Hair color } \\
\hline Dark & reference & reference & reference & reference & reference & reference \\
\hline Light & $0.51(0.06-4.27)$ & $0.40(0.17-1.91)$ & $0.29(0.08-1.08)$ & $0.22(0.05-1.09)$ & $0.57(0.16-2.11)$ & $0.75(0.09-6.40)$ \\
\hline \multicolumn{7}{|c|}{ Familial skin cancer history } \\
\hline No & reference & reference & reference & reference & reference & reference \\
\hline Yes & $0.24(0.08-0.71)$ & $0.52(0.15-1.75)$ & $1.46(0.47-4.50)$ & $1.18(0.25-5.54)$ & $0.86(0.29-2.49)$ & $0.78(0.23-2.68)$ \\
\hline \multicolumn{7}{|c|}{ Previous sunburns during childhood } \\
\hline No & reference & reference & reference & reference & reference & reference \\
\hline Yes & $3.11(1.44-6.76)$ & $1.10(0.51-1.91)$ & $1.96(1.15-3.32)$ & $2.41(1.15-5.06)$ & $0.78(0.48-1.27)$ & $1.32(1.07-2.51)$ \\
\hline \multicolumn{7}{|c|}{ Common naevi } \\
\hline No & reference & reference & reference & reference & reference & reference \\
\hline Yes & $0.77(0.37-1.57)$ & $1.14(0.54-2.42)$ & $1.12(1.05-1.88)$ & $1.67(1.21-3.97)$ & $0.70(0.40-1.22)$ & $1.00(0.48-2.09)$ \\
\hline
\end{tabular}

†Adjusted for age, gender, educational status. 
tively few modifiable factors that can be addressed. For example, factors such as gender and age are not amenable to intervention; however, the identification of these factors can assist in ensuring that subsequent intervention strategies are effectively targeted. On the whole, those people who are included in high risk groups are more likely to adapt personal protective measures [32,35] most probably due to the fact that they perceive themselves as at risk for the development of skin cancer [34] and they are aware of the danger. Therefore, it is important that preventive programs in this area are based on reference to behavioural data that assesses a range of sun protective measures in conjunction with knowledge and attitudinal parameters [42].

Primary prevention campaigns are recommended so as to increase the awareness of population regarding the risk factors for melanoma, the potential harm of overexposure to the sun and the importance of compliance with the suggested preventive measures. Furthermore, such kind of campaigns should primarily focus to children and adolescents as a recent study performed to a Greek sample of adolescents showed that small percentages of the sample (38\%) knew that melanoma was a type of skin cancer where as half of them were unaware of what melanoma was [43]. The same study reported that half of the adolescents did not wear a sunhat or stayed in the shade and either did not use a sunscreen properly or use one with insufficient sun protection factor [43]. Moreover, preventive campaigns should take into account that several studies have reported a diagnostic peak for melanoma diagnosis during the summer months most probably due to the change in clothing habits, the increased visibility of the skin and sustained sunburns due to recent sun exposure. As a result, such findings suggest that preventive campaigns should emphasize and promote a better skin awareness among population especially during summer period.

However, the relationship between knowledge, sun protective behaviour and the mediating effect of sun protective attitudes and attitudes towards tanning and sunbathing are still not fully understood. Sunscreen can effectively reduce sunburn rates and the development of solar keratosis [16] and has been recommended as a central part of sun protection since public health campaigns first started. A long-term, coordinated multi-level approach to increase sun protection that uses a range of strategies needs to be developed over the next few years. Messages need to be specifically targeted for at-risk groups (especially by age, gender and skin type), and approaches need to be refreshed and updated regularly, particularly to capture young markets. Reduction of the prevalence of sunburn currently observed in children and adolescents is of great priority. A reduction in sunburn rates may be best facilitated by the increased use of protective clothing, hats and seeking shade. Melanoma needs to remain on the social agenda through a variety of mechanisms, and innovative new strategies are needed to achieve or maintain high levels of awareness and sun protective behaviour [17].

In conclusion, this study poses the necessity of targeting those individuals at risk of melanoma through campaigns which should be implemented in a wide scale in Greece. These campaigns should organize future preventive strategies aiming to foster sun protection behaviours whereas further studies with a multivariate design aiming to extract confounding factors of sun protective behaviour and interactions between knowledge, attitudes and behaviours seem necessary.

\section{STUDY LIMITATION}

The study design allowed us to perform the analysis to a representative sample of nurses. Additionally, this study adds important information to the limited body of knowledge regarding the relationship between the adherence to protective behavioural measures and high risk groups for the development of skin cancer. On the other hand, there are a number of limitations within our study. Firstly, this is a study conducted among nurses, a study population who might be more informed about skin cancer risk factors and as a result be more willing to adapt personal protective measures as previous knowledge about the danger of sun exposure is associated with increased sun protection, and therefore our results may not be generalisable to the general population. Finally, the participants self reported assessment of the number of common naevi they have, might have affected the estimates as studies have revealed great heterogeneity among the methods of counting naevi: self-assessment, the interviewer's and trained clinician's examination [37].

\section{REFERENCES}

[1] Billiard, J.L., Cox, B. and Semenciw, R. (1999) Trends by anatomic site in the incidence of cutaneous malignant melanoma in Canada 1969-93. Cancer Causes Control, 10, 407-416. doi:10.1023/A:1008964621225

[2] Friedman, R.J., Rigel, D.S., Silverman, M.K., Kopf, A.W. and Vossaert, K.A. (1991) Malignant melanoma in the 1990s: The continued importance of early detection and the role of physician examination and self examination of the skin. Cancer Journal for Clinicians, 41, 201-226. doi:10.3322/canjclin.41.4.201

[3] Hurwitz, S. (1998) The sun and sunscreen protection: Recommendations for children. Journal of Dermatologic Surgery \& Oncology, 14, 657-660.

[4] Marks, R., Jolley, D., Lectsas, S. and Foley, P. (1999) 
The role of childhood exposure to sunlight in the development of solar keratoses and negative non-melanocytic skin cancer. The Medical Journal of Australia, 152, 6266.

[5] Stern, R., Weinstein, M. and Baker, S. (1986) Risk reduction for non-melanoma skin cancer with childhood sunscreen use. Archives of Dermatology, 122, 537-545. doi:10.1001/archderm.1986.01660170067022

[6] Rhodes, A., Weinstock, M., Fitzpatrickl, T., Mihm M.C., Jr. and Sober, A.J. (1987) Risk factors for cutaneous melanoma: A practical method of recognizing predisposed individuals. The Journal of the American Medical Association, 258, 3146-3154. doi:10.1001/jama.1987.03400210088032

[7] Green, A., Bain, C., McLennan, R. and Siskind, V. (1986) Risk factors for cutaneous melanoma in Queensland. Recent Results in Cancer Research, 102, 76-97. doi:10.1007/978-3-642-82641-2_6

[8] Elwood, J.M. and Jopson, J. (1997) Melanoma and sun exposure: An overview of published studies. International Journal of Cancer, 73, 198-203. doi:10.1002/(SICI)1097-0215(19971009)73:2<198::AID -IJC6>3.0.CO;2-R

[9] Vagero, D., Ringback, G. and Kiviranta, H. (1986) Melanoma and other tumours of the skin among office, other indoor and outdoor workers in Sweden 1961-1979. British Journal of Cancer, 53, 507-512. doi:10.1038/bjc.1986.80

[10] Gallagher, R.P., McLean, D.I., Yang, C.P., Coldman, A.J., Silver, H.K., Spinelli, J.J. and Beagrie, M. (1990) Suntan, sunburn, and pigmentation factors and the frequency of acquired melanocytic nevi in children. Similarities to melanoma: The Vancouver Mole Study. Archives of Dermatology, 126, 770-776.

doi:10.1001/archderm.126.6.770

[11] Kelly, J.W., Rivers J.K., MacLennan, R., Harrison, S., Lewis, A.E. and Tate, B.J. (1994) Sunlight: A major factor associated with the development of melanocytic nevi in Australian schoolchildren. Journal of the American Academy of Dermatology, 30, 40-48. doi:10.1016/S0190-9622(94)70005-2

[12] Aalborg, J., Morelli, J.G., Mokrohisky, S.T., et al. (2009) Tanning and increased nevus development in very light-skinned children without red hair. Archives of Dermatology, 145, 989-996.

doi:10.1001/archdermatol.2009.193

[13] Manson, J.E., Rexrode, K.M., Garland, F.C. and Weistock, M.A. (2000) The case for a comprehensive national campaign to prevent melanoma and associated mortality. Epidemiology, 11, 728-734. doi:10.1097/00001648-200011000-00021

[14] Armstrong, B.K. and Kricker, A. (2001) The epidemiology of UV induced skin cancer. Journal of Photochemistry and Photobiology B: Biology, 63, 8-18. doi:10.1016/S1011-1344(01)00198-1

[15] Turner, M. (1998) Sun safety: Avoiding noonday sun, wearing protective clothing, and the use of sunscreen. Journal of the National Cancer Institute, 90, 1854-1855. doi:10.1093/jnci/90.24.1854

[16] Pruim, B. and Green, A. (1999) Photobiological aspects of sunscreen reapplication. Australasian Journal of Dermatology, 40, 14-18. doi:10.1046/j.1440-0960.1999.00309.x

[17] Stanton, W.R., Janda, M., Baade, P.D. and Anderson, P. (2004) Primary prevention of skin cancer: A review of sun protection in Australia and internationally. Health Promotion International, 19, 369-378. doi:10.1093/heapro/dah310

[18] Berwick, M., Fine, J. and Bolognia, J.L. (1992) Sun exposure and sunscreen use a community skin cancer screening. Preventive Medicine, 21, 302-310. doi:10.1016/0091-7435(92)90029-H

[19] Nikolaou, V., Stratigos, A.J., Antoniou, C., Sypsa, V., Avgerinou, G., Danopoulou, I., Nicolaidou, E. and Katsambas, A.D. (2009) Sun exposure behaviour and protection practices in a Mediterranean population: A questionnaire-based study. Photodermatology, Photoimmunology \& Photomedicine, 25, 132-137. doi:10.1111/j.1600-0781.2009.00424.x

[20] Hill, D., White, V., Marks, R., Theobald, T., Borland, R. and Roy, C. (1992) Melanoma prevention: Behavioural and non-behavioural factors in sunburn among and Australian urban population. Preventive Medicine, 21, 654669. doi:10.1016/0091-7435(92)90072-P

[21] Hill, D., White, V., Marks, R. and Borland, R. (1993) Changes in sun-related attitudes and behaviours, and reduced sunburn prevalence in a population at high risk of melanoma. European Journal of Cancer Prevention, 2, 447-456. doi:10.1097/00008469-199311000-00003

[22] Hall, H.I., May, D.S., Lew, R.A., Koh, H.K. and Nadel, M. (1997) Sun protection behaviours of the U.S. white population. Preventive Medicine, 26, 401-407. doi:10.1006/pmed.1997.0168

[23] Jackson, A., Wilkinson, C. and Pill, R. (1999) Moles and melanomas-Who's at risk, who knows, and who cares? A strategy to inform those at risk. British Journal of General Practice, 49, 199-203.

[24] Schofield, P.E., Freeman, J.L., Dixon, H.G., Borland, R. and Hill, D.J. (2001) Trends in sun protection behavior among Australian young adults. Australian New Zealand Journal of Public Health, 25, 62-65. doi:10.1111/j.1467-842X.2001.tb00552.x

[25] Abroms, L., Jorgensen, C.M., Sothwell, B.G., Geller, A.C. and Emmons, K.M. (2003) Gender differences in young adults' beliefs about sunscreen use. Health Education and Behavior, 30, 29-43. doi:10.1177/1090198102239257

[26] Devos, S.A., Baeyens, K. and Van Hecke, L. (2003) Sunscreen use and skin protection behavior on the Belgian beach. International Journal of Dermatology, 42, 352356. doi:10.1046/j.1365-4362.2003.01665.x

[27] Weinstock, M.A. (2000) Sunscreen. Current Opinion in Oncology, 12, 159-162. doi:10.1097/00001622-200003000-00011

[28] Nikolaou, V.A., Sypsa, V., Stefanaki, I., Gogas, H., Papadopoulos, O., Polydorou, D., Plaka, M., Tsoutsos, D., Dimou, A., Mourtzoukou, E., Korfitis, V., Hatziolou, E., Antoniou, C., Hatzakis, A., Katsambas, A. and Stratigos, A.J. (2008) Risk associations of melanoma in a Southern European population: Results of a case/control study. Cancer Causes Control, 19, 671-679. doi:10.1007/s10552-008-9130-0

[29] Foot, G., Girgis, A., Boyle, C.A. and Sanson-Fisher, R.W. (1993) Solar protection behaviours: A study of beachgo- 
ers. Australian Journal of Public Health, 17, 209-214. doi:10.1111/j.1753-6405.1993.tb00137.x

[30] Weinstock, M.A., Rossi, J.S., Redding, C.A. Maddock, J.E. and Cottrill, S.D. (2000) Sun protection behaviors and stages of change for the primary prevention of skin cancers among beachgoers in southeastern New England. Annals of Behavioral Medicine, 22, 286-293. doi:10.1007/BF02895664

[31] Pruim, B., Wright, L. and Green, A. (1999) Do people who apply sunscreens, re-apply them? Australasian Journal of Dermatology, 40, 79-82. doi:10.1046/j.1440-0960.1999.00325.x

[32] Gandini, S., Sera, F., Cattaruzza, M.S., Pasquini, P., Abeni, D., Boyle, P. and Melchi, C.F. (2005) Meta-analysis of risk factors for cutaneous melanoma: I. Common and atypical naevi. European Journal of Cancer, 41, 28-44. doi:10.1016/j.ejca.2005.03.034

[33] Gandini, S., Sera, F., Cattaruzza, M.S., Pasquini, P., Picconi, O., Boyle, P. and Melchi, C.F. (2005) Metaanalysis of risk factors for cutaneous melanoma: II. Sun exposure. European Journal of Cancer, 41, 45-60. doi:10.1016/j.ejca.2004.10.016

[34] Stanton, W.R., Chakma, B., O’Riordan, D.L. and Eyeson-Annan M. (2000) Sun exposure and primary prevention of skin cancer for infants and young children during autumn/winter. Australian and New Zealand Journal of Public Health, 24, 178-184. doi:10.1111/j.1467-842X.2000.tb00139.x

[35] Broadstock, M., Borland, R. and Gason, R. (1992) Effects of suntan on judgements of healthiness and attarctiveness by adolescents. Journal of Applied Social Psychology, 22, 157-172. doi:10.1111/j.1559-1816.1992.tb01527.x

[36] Armstrong, B.K. (1988) Epidemiology of malignant melanoma: Intermittent or total accumulated exposure to the sun. Journal of Dermatologic Surgery \& Oncology, 14, 835-849.

[37] Lower, T., Girgis, A. and Sanson-Fisher, R. (1998) The Prevalence and Predictors of Solar Protection Use among Adolescents. Preventive Medicine, 27, 391-399. doi:10.1006/pmed.1998.0309

[38] Saridi, M., Pappa, V., Kyriazis, I., Toska, A., Giolis, A., Liachapoulou, A., Skliros, E. and Birbas, K. (2009) Knowledge and attitudes to sun exposure among adolescents in Korinthos, Greece. Rural Remote Health, 9, 1162.

[39] Nikolaou, V., Stratigos, A.J., Antoniou, C., Sypsa, V., Stefanaki, I., Papadopoulos, O., Danopoulou, I., Hampsas, G., Plaka, M., Polydorou, D. and Katsambas, A.D. (2007) Seasonal pattern of the diagnosis of cutaneous melanoma: A hospital-based study in a Mediterranean country. International Journal of Dermatology, 46, 1136-1140. doi:10.1111/j.1365-4632.2007.03289.x

[40] Thompson, S.C., Jolley, D. and Marks, R. (1993) Reduction of solar keratoses by regular sunscreen us. Journal of the American Academy of Dermatology, 329, 11471151.

[41] Mortague, M., Borland, R. and Sinclair, C. (2001) Slip! Slop! Slap! And SunSmart 1980-2000: Skin cancer control and 20 years of population based campaigning. Health Education and Behaviour, 28, 290-305. doi:10.1177/109019810102800304

[42] Cody, R. and Lee, C. (1990) Behaviours, beliefs and intentions in skin cancer prevention. Journal of Behavioural Medicine, 13, 373-389. doi:10.1007/BF00844885

[43] Hughes, B.R., Altman, D.G. and Newton, J.A. (1993) Melanoma and skin cancer: Evaluation of a health education programme for secondary schools. British Journal of Dermatology, 128, 412-417. doi:10.1111/j.1365-2133.1993.tb00201.x 